\title{
Numerical Simulation of a Compartment Fire from Burn-Up to Flashover
}

\author{
TOMOKO JOH and JUNJI MASHIGE \\ Century Research Center Corporation \\ 3-6-2, Nihonbash Honcho, Chuo-ku, \\ Tokyo 103, Japan
}

\section{OSAMI SUGAWA}

Center for Fire Science and Technology

Science University of Tokyo

Yamasaki 2641, Noda-shi

Chiba 278, Japan

\author{
TOMOAKI YOSHIKAWA \\ Meteorological Research Institute \\ Japan Meteorological Agency \\ 1-1 Nagamine, Tsukuba-shi \\ Ibaragi 305, Japan
}

\begin{abstract}
The field model was adopted to three dimensional simulation of the time sequence of hot air temperature, wind vector, pressure and wall temperature in an early stage of a compartment fire, including generations and diffusions of smoke and toxic gases. This field model was applied to analysis of two model fire cases. One is a case of an early stage of a compartment fire from burn-up at a table extension up to the wall, and the other is a case of sudden hot air flow-out through a broken window by glass. Both cases were verified through the full. scale experiments. The calculated values such as temperature and velocities agreed reasonably with the experimental results. In the latter case, the outward flow velocity showed remarkably strong outflow velocity after the window break as a character of "flash over".
\end{abstract}

Key Words : field model, simulation, compartment fire, change of boundary condition, three dimensional flow

\begin{abstract}
1. INTRODUCTION
A numerical computation model was developed from 1982 to 1986 [1,2] by the staff of the Center for Fire Science and Technology, Science University of Tokyo. We developed numerical computation model based on the Hasemi's work [3]. The model for three dimensional flow can simulate the time variation of hot air temperature, wind vector, pressure and wall temperature in an early stage of a compartment fire including generations and diffusions of smoke and combustion gases. The computational model for the fire situation from burn-up to flash over in a semi-enclosed compartment/space is very useful not only for designing fire countermeasures in residences and offices but also for the environmental control in a cabin of car, train, and airplane.
\end{abstract}

\section{GOVERNING EQUATIONS}

\subsection{FIELD MODEI}

\section{(a) BASIC EQUATIONS}

Three-dimensional flow with buoyant force was employed. 
- Equation of momentum,

$\frac{\partial \overline{\rho u}_{i}}{\partial t}+\frac{\partial \overline{\rho u}_{i} \bar{u}_{j}}{\partial x_{j}}=\frac{\partial \bar{P}_{\partial x_{i}}}{\partial}+\frac{\partial}{\partial x_{j}}\left(\bar{\sigma}_{i j}+K\left(\frac{\partial \overline{\rho u}_{i}}{\partial x_{j}}+\frac{\partial \overline{\rho u}_{j}}{\partial x_{i}}\right)-\delta_{i j} \bar{\rho} g\right.$

- Equation of continuity,

$\frac{\partial \bar{\rho}}{\partial t}+\frac{\partial \bar{\rho}_{i}}{\partial x_{i}}=0$

- Equation of thermal energy,

$\vec{\rho} \frac{\partial \bar{h}}{\partial t}+\frac{\partial \overline{\rho u_{i}} \bar{h}}{\partial x_{i}}=\frac{\partial}{\partial x_{i}}\left(\kappa \frac{\partial \bar{T}}{\partial x_{i}}+\rho K \frac{\partial \bar{h}}{\partial x_{i}}\right)+\bar{Q}+\bar{h} \frac{\partial \overline{\rho u} i}{\partial x_{i}}, K=\bar{q}^{1 / 2} \ell, h=C_{p} T$ (3)

- Equation of momentum energy,

$$
\begin{aligned}
& \frac{\partial \bar{\rho} \bar{q}}{\partial \bar{t}}+\frac{\partial \overline{\rho u}_{i} \bar{q}}{\partial x_{i}}=\frac{\partial}{\partial x_{i}}\left(\bar{\rho} K \frac{\partial \bar{q}}{\partial x_{i}}\right)+\mu \frac{\partial^{2} \bar{q}}{\partial x^{2}}+g K \frac{\partial \bar{\rho}}{\partial x_{3}}-\bar{\rho} \bar{\varepsilon} \\
& +K \frac{\partial \bar{u}_{t}}{\partial x_{j}}\left(\frac{\partial \overline{\rho u}_{i}}{\partial x_{j}}+\frac{\partial \overline{\rho u}_{j}}{\partial x_{i}}\right)
\end{aligned}
$$

- Equation of gas diffusion,

$$
\frac{\partial \bar{\rho}_{\alpha}}{\partial t}+\frac{\partial \bar{\rho}_{\alpha} \bar{u}_{i}}{\partial x_{i}}=\frac{\partial}{\partial x_{i}}\left(K_{\rho} \frac{\partial \bar{\rho}_{\alpha}}{\partial x_{i}}-J_{\alpha i}\right)+\bar{\phi}_{\alpha}
$$

For the computation air pressure, a Poisson type equation was constructed, by combining equation (1) differentiated with $X$, and equation (2) differentiated with time.

$$
\frac{\partial^{2} \bar{p}}{\partial t}=\frac{\partial^{2} \bar{\rho}}{\partial t^{2}}+\frac{\partial^{2}}{\partial x_{i} \partial x_{j}}\left(\bar{\sigma}_{i j}+K\left(\frac{\partial \overline{\rho u_{i}}}{\partial x_{j}}+\frac{\partial \overline{\rho u}_{j}}{\partial x_{i}}\right)-\overline{\rho u}_{i} \bar{u}_{j}\right)-g \frac{\partial \bar{\rho}}{\partial x_{3}}
$$

Equation (6) can be solved through the relaxation method under the assumption that;

$$
\bar{\rho}=\mathrm{P}_{0}<\mathrm{R} \overline{\mathrm{T}}
$$

(b) DTEFERENTIATION AND TIME STEP

Each equation was transformed to the differential form and solved it numerically. The scheme of differentiation was set in various proper types, considering the accuracy of solution and the stability of computation. In order to satisfy the computation stability condition, variable time step was set as follows.

$$
\Delta t \leq\left\{\frac{6(K+\mu)}{\Delta x^{2}}+\frac{|\bar{u}|+|\bar{v}|+|\bar{w}|}{\Delta x}\right\}^{-1}
$$

(c) BOUNDARY CONDITIONS

SOLID BOUNDARY

Normal component of velocity at the boundary:

$$
\mathrm{U}_{j}^{*}=0, \quad \rho^{*} \mathrm{U}_{j}^{*}=0
$$


Parallel component of velocity along the boundary:

$$
U_{i}^{*}=-U_{i}, \quad \rho^{* U_{i}^{*}}=-U_{i}
$$

Momentum at the boundary:

$$
q^{*}=-q
$$

Temperature on the solid surface

$$
\begin{aligned}
& \mathrm{T}^{*}=\mathrm{T} \text { (adiabatic wall) } \\
& \mathrm{T}^{*} \quad \begin{array}{c}
\text { (non-adiabatic wall), is computed from the } \\
\text { thermal energy balance equation on the wall. }
\end{array}
\end{aligned}
$$

FREE BOUNDARY

Temperature : $T^{*}=T_{0}$ (inflow)

$$
\text { T (outflow) }
$$

Momentum $: q^{*}=q_{0}($ inflow $)$

$$
=q \text { (outflow) }
$$

Pressure : $\mathrm{P}^{*}=\mathrm{P}_{\mathrm{O}}-\rho_{\mathrm{O}}$ gh (inflow)

Air density : $\rho^{*}=\rho$ (inflow)

$$
=\rho_{\mathrm{O}} \text { (outflow) }
$$

Velocity components : $u^{*}=u, \quad v^{*}=v$ and $w^{*}$ is the solution of

$$
\frac{\partial \rho *_{\mathrm{u}} *}{\partial \mathrm{X}}+\frac{\partial \rho *_{\mathrm{v}} *}{\partial \mathrm{y}}+\frac{\partial \rho *_{\mathrm{w}} *}{\partial z}=0
$$

SOLID BOUNDARY BREAK

The Break of a window glass or/and a door is computed according to the criteria by experimental results. Boundary conditions are exchanged solid boundary to free boundary at the break time.

\subsection{COMBUSTION MODEL}

The combustion of a solid material can be represented by an empirical relation for the combustion rate as follows:[4]

$$
\begin{array}{ll}
R B=a t^{2} & \text { for } t<t 1, \\
R B=\text { constant } & \text { for } t \text { t } 1
\end{array}
$$

A solid material decreases in proportion to the combustion rate which controlled generation rate of the pyrolysis gases. The constitutions of pyrolysis gases for a wood and a urethane form are employed as $\mathrm{C}: 43.5 \%, \mathrm{H}: 5.2 \%, 0: 38.8 \%$, and residue $13.0 \%$. We assuned that the components, $\mathrm{C}, \mathrm{H}$ and $\mathrm{O}$ of pyrolysis gases, burn in the generated mesh cell using the natural atmospheric oxygen gas. 
The combustion produces heat in proportion to the oxidation reaction. Chemical equations in the case of stoichiometric combustion under sufficient oxygen supply from the atmosphere will be

$$
\begin{aligned}
& \mathrm{C}+\mathrm{O}_{2} \rightarrow \mathrm{CO}_{2}, \\
& \mathrm{H}_{2}+1 / 2 \mathrm{O}_{2} \rightarrow \mathrm{H}_{2} \mathrm{O} .
\end{aligned}
$$

If the oxygen gas is insufficient for stoichiometric combustion, the remaining pyrolysis gas flows to the next mesh and reacts with the natural oxygen gas, supplied with diffusion from the surrounding meshes.

The combustion of ordinary home furniture and carpets was also computed using the pyrolysis gas data obtained in a set of experiments. $[5,6,7]$ The generation and diffusion of smoke and combustion gases are easily estimated using the combustion rate and the diffusion equation (5), since their contributions to combustion are negligible for very thin concentration except $C O$, compared with $\mathrm{C}$ and $\mathrm{H}$.

\subsection{RADTATTON MODEE}

Radiation energy from the flame mesh over $300^{\circ} \mathrm{C}$ and smoke mesh over $200^{\circ} \mathrm{C}$ were estimated with the equation $\mathrm{S}=\mathrm{T}^{4}$, using emissivity values of 0.9 for $\mathrm{T}>573 \mathrm{~K}$, from the cell of $\mathrm{T}=473-573 \mathrm{~K}$, and $\sigma$ is Stefan-Boltzmann constant. The radiation energy from the cell of $\mathrm{T}<$ $473 \mathrm{~K}$ is the same order of atmospheric radiation condition, then the exchanges of radiation energy among the meshes lower than $\mathrm{T}=474 \mathrm{~K}$ were omitted.

Furthermore, the following assumptions were employed for efficiency of computations:

(a) The exchange of radiation energy between hot meshes at the radiative temperature level was regarded as zero.

(b) The clean air mesh absorbs no radiation energy and all radiation directly reaches to a solid surface.

(c) The out flow rate of smoke is given empirically by the following equation.

$$
\phi=\frac{\partial C_{S}}{\partial t}=\frac{\partial}{\partial t}\left(\frac{K \cdot R B}{V}\right)
$$

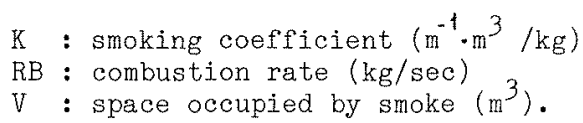

2.4 THERMAL ENERGY BALANCE AT THE WALL

The exchange of radiation between hot air mesh with the radiation temperature contacting the wall surface was estimated in accordance with their temperature differential. The radiation energy emitted from an air cell is:

$$
\begin{aligned}
& R=\varepsilon \cdot \sigma \cdot T^{4} \cdot \Delta X^{4} \cdot \text { Men } \\
& \text { Men : number of radiative mesh surface }(1-6) \\
& \varepsilon: \text { emissivity (same as defined in } 2 \cdot 3) \\
& T: \text { temperature }(K)
\end{aligned}
$$


The energy budget on the wall surface is then estimated as:

$S_{W}=\left(R \cdot \varepsilon \cdot \sigma \cdot \gamma^{4} \cdot \Delta X^{2}\right) \cdot \omega / 4 \pi$

$\omega=$ solid angle of $\Delta x^{2}$ from the center of a distant mesh cell.

\section{NUMERICAL SIMULATION OF THE FULL SCALE COMPARTMENT FIRE}

3.1 AN EARLY STAGE FROM BURN-UP FROM AT A TABLE TO THE WALL

An early stage of the compartment fire was computed from burn up at a table combustion to extension to the contacting wall. The room size, table arrangement are shown in Figure 1, and $7 \times 7 \times 11$ computation meshes were emplyed. The door was always open in this case. The table occupied 9 meshes, as is shown in Figure 2, and their combustion rate was given by the experiment result as follows:

$$
\begin{aligned}
& R B=(0.14 / 82.52) t^{2} / 15 \quad \text { for } 0<t<82.5 \mathrm{sec} \\
& R B=((0.35 / 31.5) t-0.776) / 15 \quad \text { for } 82.5<t<114 \text { sec } \\
& \left.R B=(-0.24 / 962)(t-114)^{2}+0.49\right) / 15 \text { for } \quad t>114 \mathrm{sec}
\end{aligned}
$$

Pyrolysis gas from the table was regarded to be the same as a wood and physical characteristics of the wall material are given in Table 1 .

Table 1 Physical Characteristics of wall

\begin{tabular}{ll}
\hline density & $: 588 \mathrm{~kg} / \mathrm{m}^{3}$ \\
latent heat & $: 1313.9 \mathrm{kcal} / \mathrm{kg}$ \\
specific heat & $: 0.38 \mathrm{kcal} / \mathrm{kg} \mathrm{deg}$ \\
content of oxygen $: 38.31 \mathrm{wt. \%}$ & \\
thermal conductivity $: 2.667 \times 10^{-5} \mathrm{kcal} / \mathrm{m} \mathrm{sec} \mathrm{deg}$ \\
\hline
\end{tabular}

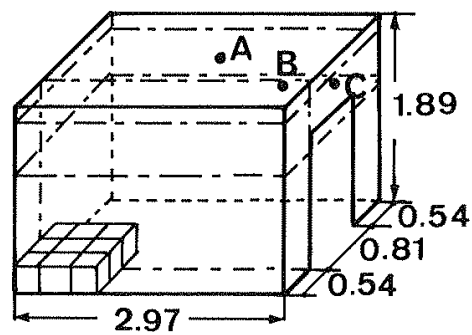

Figure 1 Sketch of the full scale compartment for fire test. (unit:m)

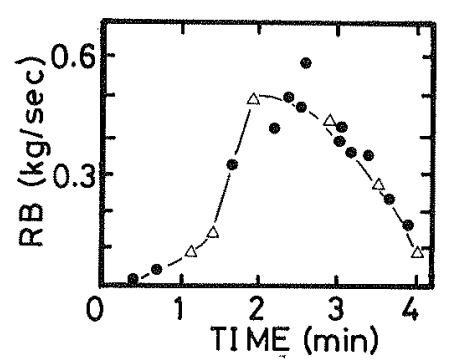

Figure 2 Time history of burning rate. data, $\Delta$ chosen as input data.

\section{$\langle$ RESULT OF COMPUTATION - CASE 1)}

Though computation was carried out in all meshes for all factors continuously, representative cross sections in Figure 1 and time variation at 3 points were selected. The verification was tried by experimental data carried out in the same scale fire.

Figure 3 shows the horizontal cross sections of temperature, pressure deviation and oxygen gas concentration at the moment of fire extension on the wall. Temperature exceeded $600 \mathrm{~K}$ above the table and 
reached almost $500 \mathrm{~K}$ in the soffit. Pressure was low under the ceiling near the entrance and high on the entrance floor. Oxygen gas concentration showed a nearly reverse distribution measuring about $14 \%$ over the table, and $21 \%$ or less in the soffit. Remarkable change in these distribution patterns were not recognized between the initial and latter time of fire extension on the wall. Wind vectors in Figure 4 show a maximum of $2.0 \mathrm{~m} / \mathrm{sec}$ just over the fire, and $1.8 \mathrm{~m} / \mathrm{sec}$ under the soffit of the entrance. Air returns along the ceiling from the fire to upper part of entrance, after inflow became apparent from the lower part of the entrance to the fire. However, such a non-symmetric pattern was distinct that clockwise rotation develop in the $Y-Z$ cross section, because fire source was set in the left corner of the room.
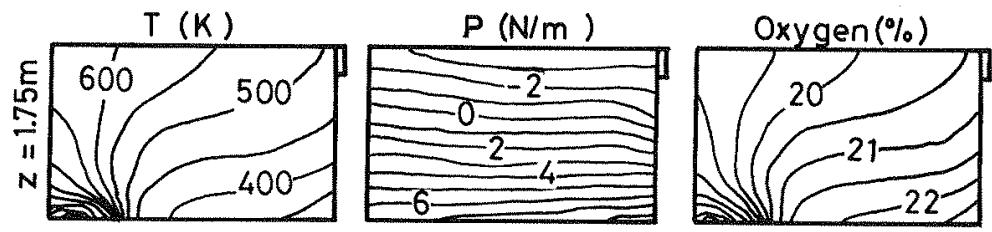

Figure 3 Temperature, pressure, and oxygen concentration on the horizontal cross section on the wall.
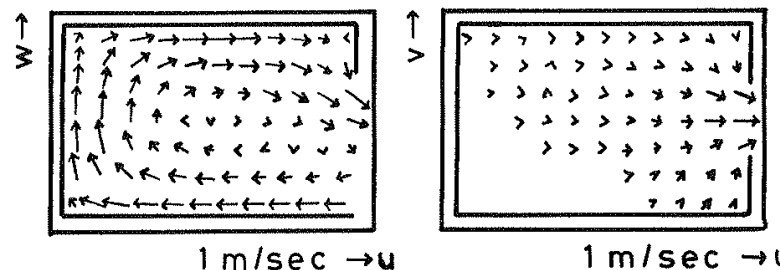

$1 \mathrm{~m} / \mathrm{sec} \rightarrow \mathrm{u}$

Figure 4 Map of wind vector. The size of the arrow under and beside the frame is $1 \mathrm{~m} / \mathrm{sec}$.

Time variations of temperature, and turbulent energy are shown in Figure 5. Temperature increased swiftly after $80 \mathrm{sec}$ and reached $600 \mathrm{~K}$ near the ceiling. Increase of pressure deviation at the 3 points was accelerated slightly with fire development. Turbulent energy and diffusion coefficient increased rapidly with the fire growth. Though turbulence at the upper entrance exceeded the level with near the ceiling for 20 sec or so after burn-up, a "jet effect", pressure rising constantly in the inner part of room was not recognized, and the maximum wind velocity and turbulence were found at the entrance. Oxygen gas
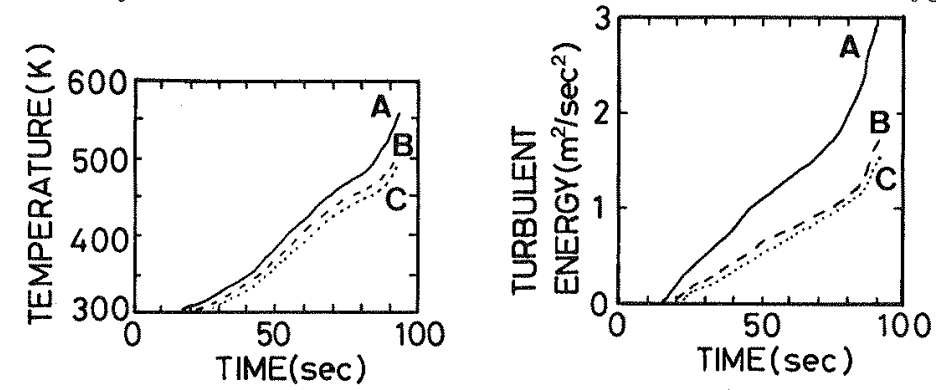

Figure 5 Time sequence of temperature and turbulent energy. The symbolize correspond to the location in figure 1. 
concentration was less than $15 \%$ in the flame mesh and $20-21 \%$ in the area from ceiling to entrance. Wall temperature showed a characteristic pattern for an inclined fire source in the left side of the room. Wall temperature just over the table reached $480 \mathrm{~K}$ before fire extension, and more than $600 \mathrm{~K}$ after the fire extension on the wall. Ceiling temperature above the fire reached $550 \mathrm{~K}$.

\subsection{SUDDEN OPENING OF WINDOW BY GLASS BREAK}

A simulation was carried out with the similar fire arrangement, as is shown in Figure 6 , in which a window above an entrance door was broken in 2 steps. Fire source was set in 2 meshes at the center of the

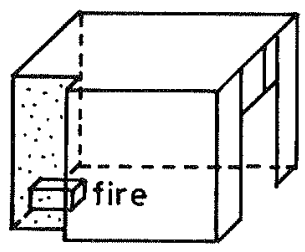

Figure 6 Sketch of the compartment. The dotted wall is cover with thick plaster boards.

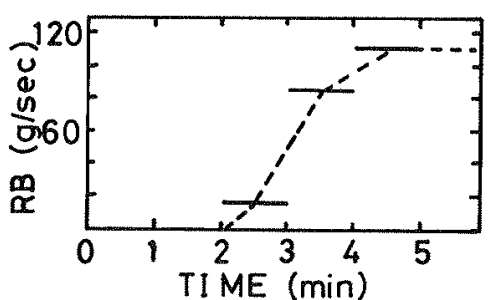

Figure 7 Time history of the burning rate.

- verified data,

- simulation.
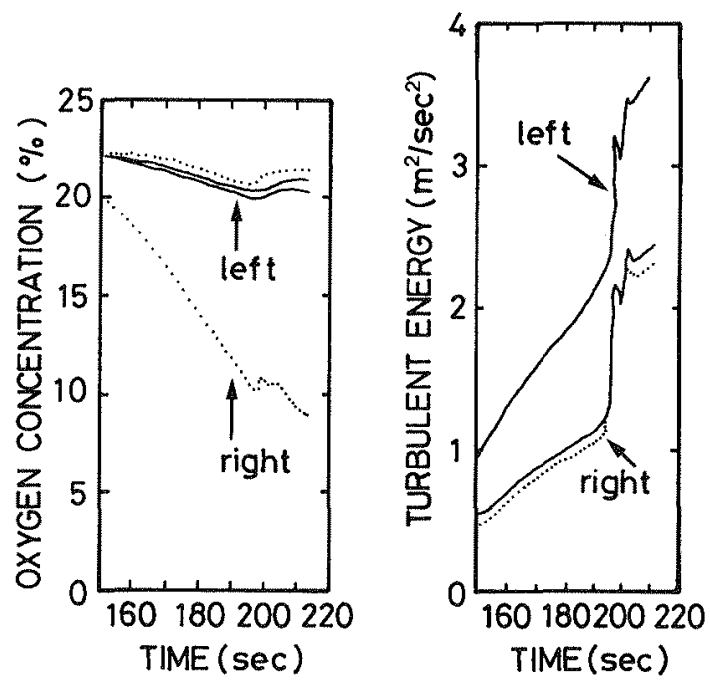

Figure 8 Time sequence of oxygen concentration and turbulent energy. 
interior section and combustion rate is shown in Figure 7 . Generation of pyrolysis gases were regarded the same component of a wood and physical parameters of wall material are given in Table 1.

< RESULP OF COMPUTATION - CASE 2>

Although temperature decreased $25 \mathrm{~K}$ at the central part near the ceiling and $50 \mathrm{~K}$ above the entrance when the right side window broke at 195 sec and left side at $200 \mathrm{sec}$, it recovered about 10 sec. Characteristic rapid decent was seen also in pressure deviation and as is shown in Figure 8 turbulent energy at the time of the window break. Oxygen concentration in the room recovered about $1 \%$ with the window break after decreasing of $3 \%$. However, oxygen gas concentration in the fire mesh recovered only slightly at the window break, and then decreased further since combustion was strengthened.

Air flow pattern showed almost no change at the window break. Figure 9 shows that blow out increased remarkably after the break as a characteristic phenomena of "flash over".
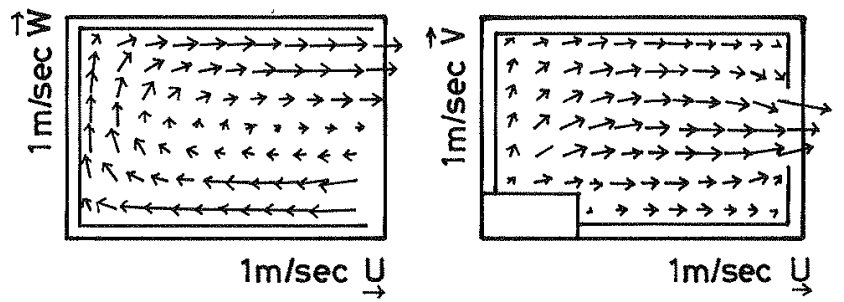

Figure 9 Map of the wind vector in the case 2. The size of the arrow under and beside the frame is $1 \mathrm{~m} / \mathrm{sec}$.

\section{RESULT OF EXPERIMENTS}

4. 1 AN EARLY STAGE FROM BURN UP AT A TABLE TO THE WALL

Temperature near the center of the ceiling was about $570 \mathrm{~K}$. Wind vector at the height of $1.25 \mathrm{~m}$ near the entrance varied from $80 \mathrm{~cm} / \mathrm{sec}$ to $90 \mathrm{~cm} / \mathrm{sec}$. Oxygen concentration near the center of the ceiling was about $15.5 \%$.

\subsection{SUDDEN OPENING OF WALL}

We could not make an experiment including window breaks of the same fire scenario as a numerical simulation. Time sequence of wind vector was measured by a supersonic anemometer shown in figure 10. Wind vector after the sudden opening of wall was about 3 times as fast as one before breakage.

\section{DISCUSSION}

5.1 AN EARLY STAGE : BURN UP AT A TABLE TO WALL

A comparison of computation and experimental result is shown in Table 2. Oxygen concentration near the ceiling was similar to one of flame meshes but was diluted by entrained air near the ceiling between the center of the ceiling and flame.

\subsection{SUDDEN OPENING OF WALL \\ A quantitative comparison was impossible but results of both}


computation and experiment showed that wind vector after sudden opening of window/wall varied from 2 to 3 times as fast as before breakage.

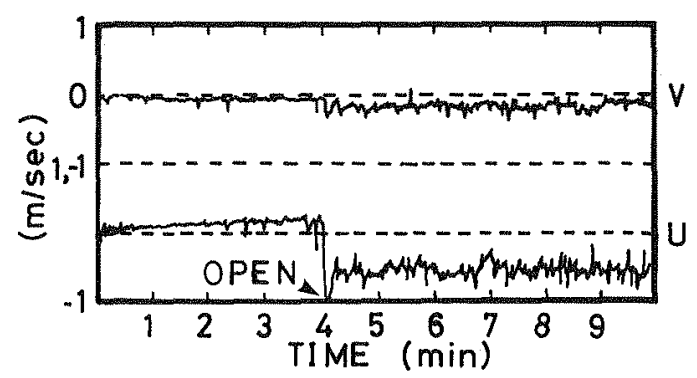

Figure 10 Time sequence of hot air velocity measure by the supersonic anemometer. The arrow means the time when the window/door opened.

Table 2 Comaprison Calculation and Experiment

\begin{tabular}{cccc} 
& Calculation & Experiment & Note \\
Temperature & about $570 \mathrm{~K}$ & about $570 \mathrm{~K}$ & \\
& $Z=175 \mathrm{~cm}$ & $Z=189 \mathrm{~cm}$ & Center of the room \\
Velocity & about $100 \mathrm{~cm} / \mathrm{s}$ & $80-90 \mathrm{~cm} / \mathrm{s}$ & \\
& $Z=108 \mathrm{~cm}$ & $Z=125 \mathrm{~cm}$ & Open Area \\
Oxygen conc. & $\begin{array}{l}13.7 \% \\
\text { fire mesh }\end{array}$ & $\begin{array}{l}15.5 \% \\
\text { near the center of the Ceiling }\end{array}$ \\
\hline
\end{tabular}

\section{CONCLUSION}

A numerical simulation model representing an early stage of a compartment fire from burn up to flash over was developed successfully following a verifiable experiment in a full scale room.

Any type of compartment fire could be simulated hereafter using combustion input data (burn up criterion, pyrolysis gas, combustion rate etc.) of interior materials and furniture obtained by experiment.

The task remains of introducing the matrix method as a way of reducing computation time in the iteration part of the relaxation method for pressure deviation.

\section{ACKNOWLEDGMENTS}

This study was carried out as a part of the special coordination program for US-Canada-Japan, "Evaluation for Gas Toxicity of Fire Produced gas and Fire Safety for Interior Materials", supported by the funds for science and technology from the Science and Technology Agency of Japanese government.

We wish to sincere thank Professor Kunio Kawagoe for many helpful discussions and suggestions for carring out this theoretical and 
experimental study.

\section{REFERENCES}

1) Handa, T., Kawagoe, K., Yoshikawa, T., Mashige, J., and Joh, T., "Numerical simulation of early stage of a compartment fire", Fire Science and Technology, Vol.4, No. 2, 91, (1984)

2) Yoshikawa, T., Mashige, J., Joh, T., and Sugawa, O., "Numerical Simulation of Early Stage of a Compartment Fire by Field Model" 9th UJNR Panel on Fire Research and Saf'ety, Boston, May 4 - 8 (1987)

3) Hasemi, Y.: "Numerical calculation of the natural convection in the compartment", BRI Research paper, No. 69, (1977)

4) H. Handa, T. Hamada, O. Sugawa, H. Fukaya, and T. Akiyama "Studies on the Motion and the Thermal Behavior of the Fire Products Through the Full Scale Corridor" Bulletin of Japan Association of Fire Science and Engineering Vol. 26, No. 2 pp.1-16, (1976)

5) Mizuno, T., and Kawagoe, K., (private communication)

6) Babrauskas, V., and Krasny, J., "Fire Behavior of Upholstered Furniture" NBS Monograph 173, National Bureau of Standards (1985)

7) Babrauskas, V., "Development of the Cone Calorimeter -- A BenchScale Heat Release Rate Apparatus Based on Oxygen Consumption", NBSIR 82-2611, National Bureau of Standards, Nov. (1982) 